\title{
Avangard: a forward-looking kolkhoz is seen as part of the past
}

\author{
Kaja Vedde $\left.\right|^{1}$ and Martti Veldi ${ }^{1}$ \\ ${ }^{1}$ Estonian university of life Sciences, Chair of landscape architecture, Tartu, Estonia
}

\begin{abstract}
Tartu in Estonia. The typical Soviet era blocks of flats overlook Lake Saadjärv and the view is met on the other side by large open fields. Back in the Soviet time it was a kolkhoz known as "Avangard" (or "avant-garde"). The name, of course, symbolised the forward-looking new Estonian Soviet state and its accompanying modernisation of the rural landscape. Today the layers of history in the settlement and the landscape around it are visible in the white brick houses built in the early days of the kolkhoz and in the favoured choice of trees planted in the same period but now all grown up. Some of those houses are not in such a great shape anymore, some continue to be used in a similar way they used to be, after the end of the kolkhoz. For example, the workshop building now hosts a company that makes dolls and the piggery has survived despite the change of owners. There are many stories to be shared by those who were part of it all. To gather those memories, and to understand how the starting of new lives for young adults of that time, interviews were carried out using the goalong technique, where the interviewed subject can recall the memories in greater detail, as they walk down the same streets as some decades ago. Although the landscape has visually changed and over two decades have passed since the ending of the Soviet regime, the mind map in peoples' heads remains vivid. The interviews revealed particular places, views, activities and memories of young adults who came here to start their independent lives, to build a future for them and for the kolkhoz at the same time at the peak of the Soviet era.
\end{abstract}

\section{Introduction}

Äksi, formerly known as Põltsamaa village before the Second World War, is a small
settlement near Tartu in Estonia. The typical Soviet era blocks of flats which comprise
the settlement overlook Lake Saadjärv. Back in the Soviet time this area was part of a
kolkhoz known as Avangard (or "avant-garde"). The name, of course, symbolised the
forward-looking new Estonian Soviet state and its accompanying modernisation of the
rural landscape. There were many things that changed during the period of collective
farms, which for Avangard was 1949-1992: not just for the landscape, but also for
people. After a few decades of hardship and struggle, the kolkhoz reached its golden
age. A new settlement, what is now known as Äksi, was built and the new houses

${ }^{1}$ Corresponding author: kaja.veddel@emu.ee 
provided a home for people coming to join the kolkhoz. Some from nearby areas, some as far as Valga in the very south of the country on the Latvian border. Among them were the three people interviewed for this project. They were all fresh graduates - young adults starting their lives, families and work in Avangard when they moved there. Their memories reveal the social bonds, the cultural richness and the benefits of being a part of a flourishing collective farm. For that we walked down the old streets, looked at photos and visited the sites of the places that were a part of their everyday life.

The aim of this paper is to explore and uncover the memories and attachments to the place belonging to a small sample of residents who lived through the kolkhoz times, were there when the new settlement was established and still live there 26 years after it stopped being a kolkhoz.

\section{Preparation for interviews}

\section{Finding interviewees}

Although Estonians are often described as cold and introverted, it doesn't usually take more than a few questions to get them to speak about the Soviet period. Occasionally this topic is overshadowed with negative connotations due to the well-known faults and crimes of the system, so care must be applied when addressing the earlier days of the era. For the Avangard case study research reported here, three people were interviewed using three different intersecting methods. First, people willing to participate and who fitted the criteria of old kolkhoz residents were found and then after getting to know them a bit, explaining what kind of information we wanted from them. While planning how the interviews would be conducted, each person was assigned a method best suited to them. During background research about Avangard while preparing for the interviews, we found how big of a role culture had played in the kolkhoz, having close ties and regular events even with Vanemuise Theatre, the main theatre in Tartu. We found that the former Avangard culture house director now runs the local library.

The first visit to the project area took place with the idea of making initial contact with the possible interviewees as well as familiarising ourselves with the setting and layout of the landscape. At the library we could easily find the former culture house director. She quickly warmed to the idea of being interviewed and found the project very fascinating. By the end of the conversation she suggested who else would be great sources of information, and by luck, one of them was in the same building at the time and also agreed to participate. During his time in the kolkhoz he had been a farm engineer, construction specialist and metal-worker. The third person was found through an acquaintance and although she doubted in the value of her memories, as shy and modest as any true Estonian grandmother, she wanted to give all her help to this project. She had moved to Avangard from distant Valga, seeking work after her graduation. She was an accountant and a dispatcher. What connects all those people is the fact that they all came to the same kolkhoz as young adults to build a future. The most active and fascinating period of their life also overlapped with the most successful period of the kolkhoz. This synchronisation and mutual effects between the two sides is what is the core of this paper.

\section{Preparing the questions}

The questions and topics for the interviews were chosen based on the guidelines and methods developed for the Modscapes project [1]. To begin with, the character of the 
kolkhoz was defined. A few keywords to summarise it would be: culture, cooperation, success, henhouse, cake factory, community. It was difficult to pass any source about the area without a mention to high quality culture activities there. The kolkhoz even had some decades long "contract of friendship" with theatre Vanemuine from Tartu [2]. Events made a good ground for people to connect and bond, also influencing the work environment to be more inspiring. That, on its own, attracted a lot of people to live and work in the heart of the kolkhoz. Thus, they began to build on the shore of Saadjärv. As a combination of all these factors, around 15 questions were selected that were centred around daily routines, events, social structure, evolution of the settlement and economical independence.

Ahead of the interviews, every person was given an explanation about what type of information and memories were important for the research. From one of the interviewees we also asked to look at any photographs she has of her Avangard life.

During the interviews, a starting question was given to the person about something that could be seen around them. In case of both walk-along and drive-along interviews (see below), we stopped if we passed an object of particular interest. Otherwise passing into a new scenery sparked new stories. However, some guiding questions were needed for topics that were not directly inspired by the scene, such as about daily routines, general changes in the environment and details of their habits.

\section{Methods}

The chosen methods of collecting memories using interviews were aimed at understanding the collectivisation in the phase where it was closest to its intended ideal. This means that by the 1970 s and 1980 s the collective farms, also specifically Avangard, had organised their models of working, they had an effective system, they had their working methods, their architecture and their agricultural machinery. For the workers, the day-to-day life was no longer a struggle. The scale this research is focused on is a local scale, just barely brushing upon the regional scale, because of the relative proximity of the living and working arrangements of the interviewees to the heart of the kolkhoz. Due to the nature of everyday life, people did not travel around the district very much and the connection even with other sections of the kolkhoz was rather weak. The interviews were carried out using two methods used in Modscapes project: the "TalkAbout" step and the "Go-Along" step.

\section{The "Talk-About" interview}

In the Talk-About interview step the interviewer sits or stands with one or more interviewees around a map to collect information about the case study area (Fig. 1.) in general and also more specific places of interest identified by the interviewees. This step seeks for an understanding of the spatial character of the area as part of people's lives [1].

This method was used for the interview conducted at the interviewee's home. We laid a map of the area in front of her and had her point out the locations she was speaking about (Fig. 1. and Fig. 2.). This was very helpful when she was talking about the construction of single family homes in her neighbourhood and the ownerships of those houses. But due to her age-related situation, the map was occasionally difficult to read. To balance that out, she had some old photos to show us and to tell stories about. 


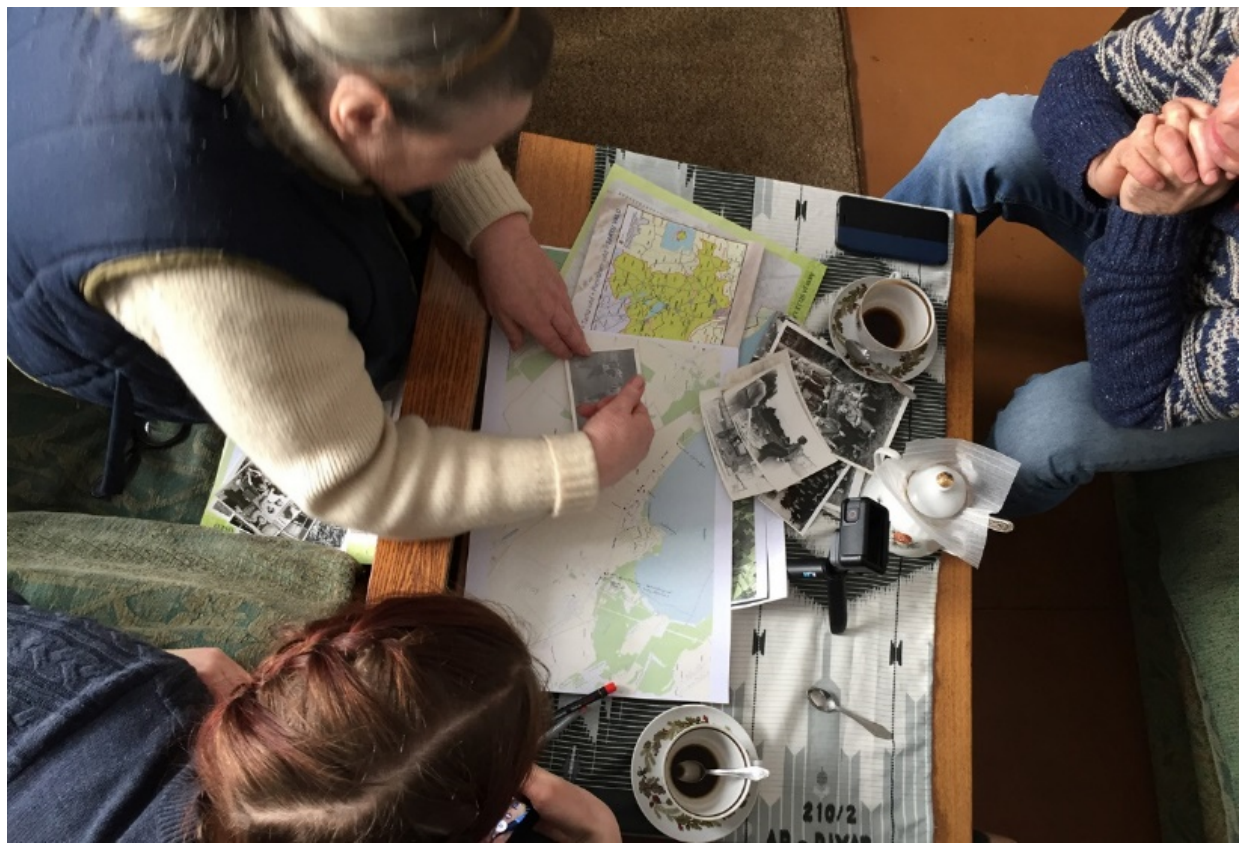

Figure 1. The Talk-About interview in action. (Source: the authors)

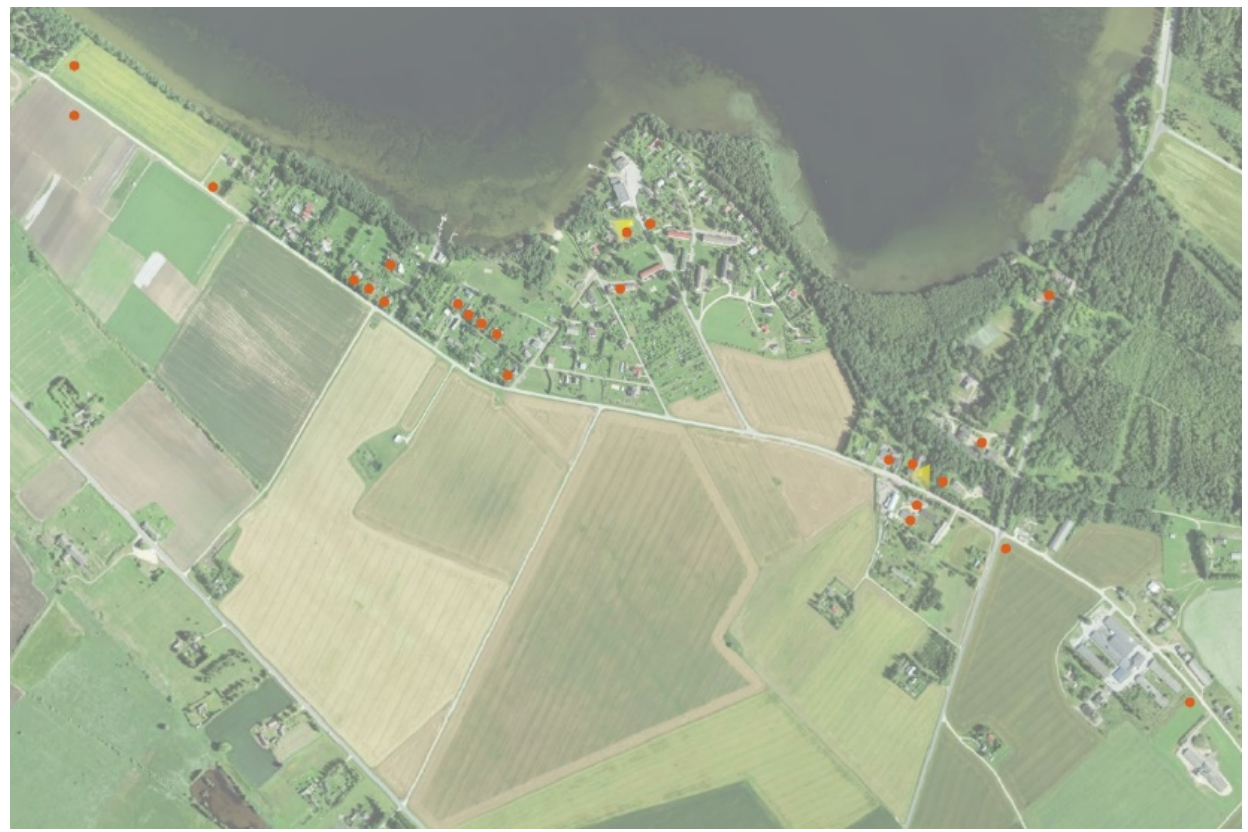

Figure. 2. Positions mentioned by the first interviewee indicated on a map of the area (source: the authors).

\section{The "Go-Along" interview}

During the Go-Along interview the interviewer moves together with one or more interviewees to collect information simultaneously about the case study area (Fig. 3.) and its actors and to explore the relationships between both now and the past. During the interview the interviewer asks questions about the area and how the interviewee is 
related to it, recording their explanations and comments throughout the whole interview [1]. For the Avangard case study, this method was performed both on foot (Fig. 5.) and by car (Fig. 4.) for two separate interviews.

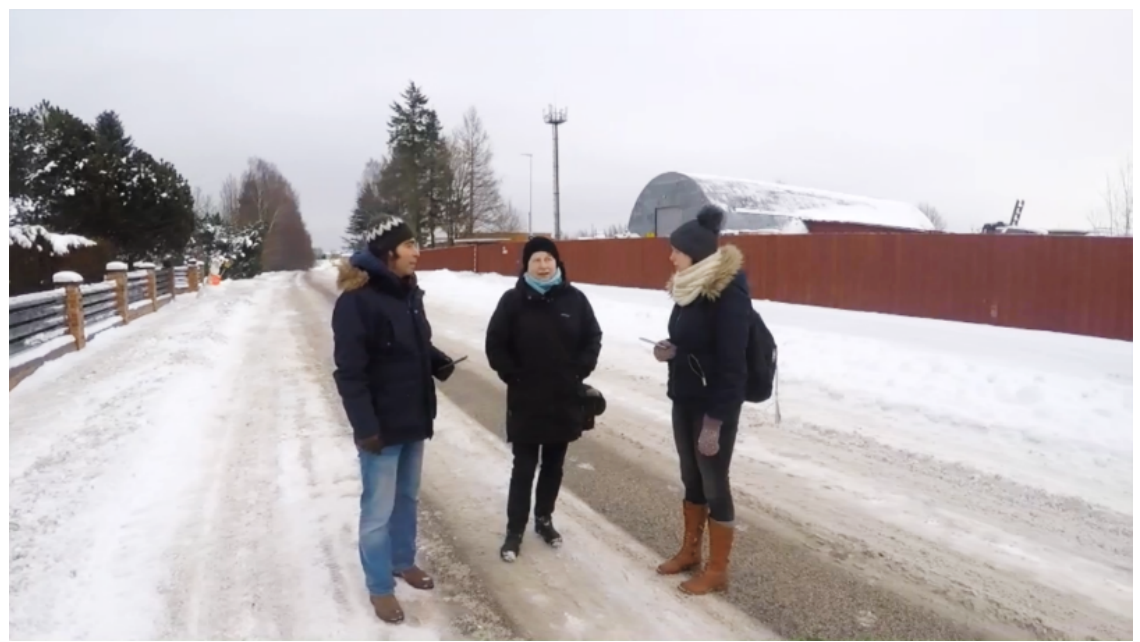

Figure. 3. The Go-Along interview in action (source: the authors).

Both of those steps were filmed using a Go-pro camera and additionally recorded with a sound recorder. In the case of the walking "Go-Along" the camera is handheld and pointed at the subject or pans the surrounding in order to capture the landscape under discussion as completely as possible. The combination of a camera and a sound recorder is essential for data analysis in the next phase because a sound recorder alone does not allow the interviewer to recall the exact objects pointed at if they are further away and not clearly named. For the "Talk-About" the camera is set on a tripod overlooking the table so the marking and pointing on the map can be clearly seen.

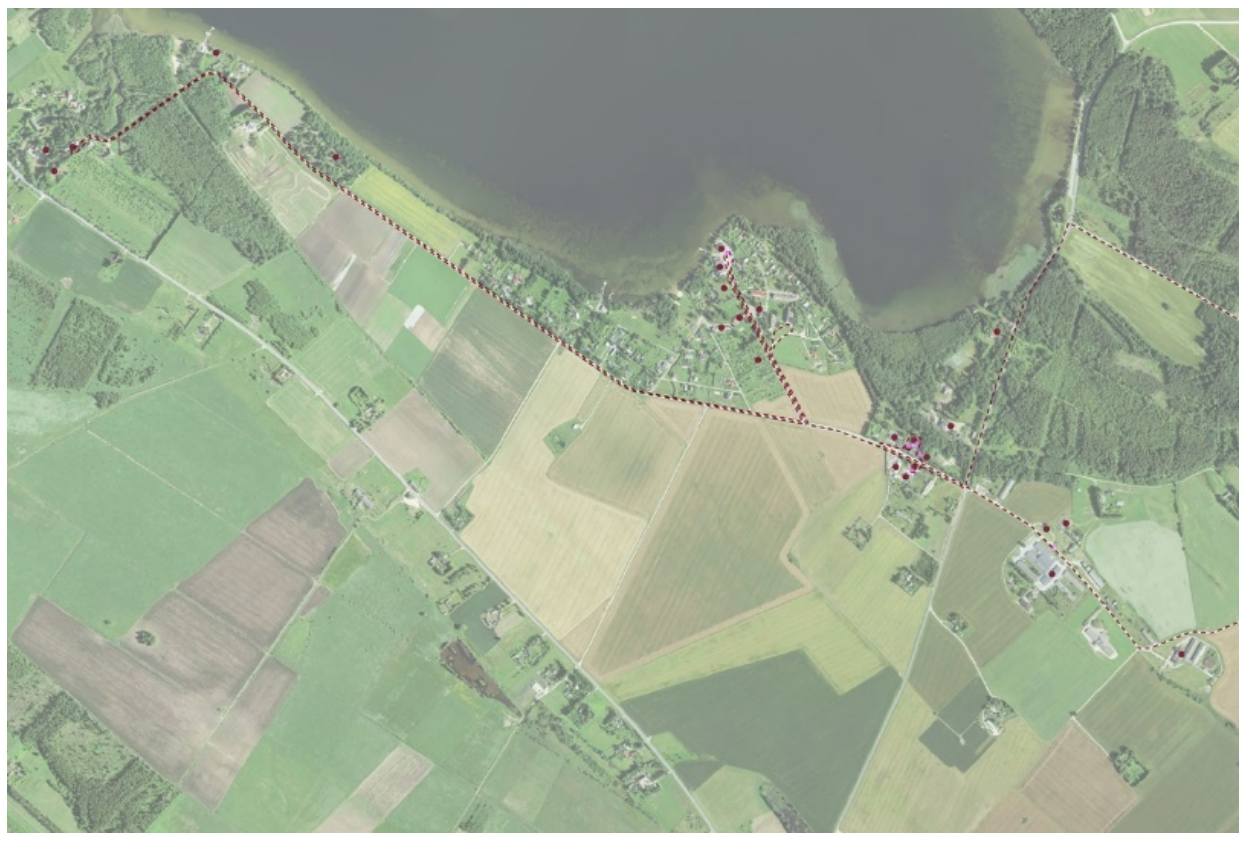

Figure. 4. The results of Go-Along interview in the car (source: the authors). 


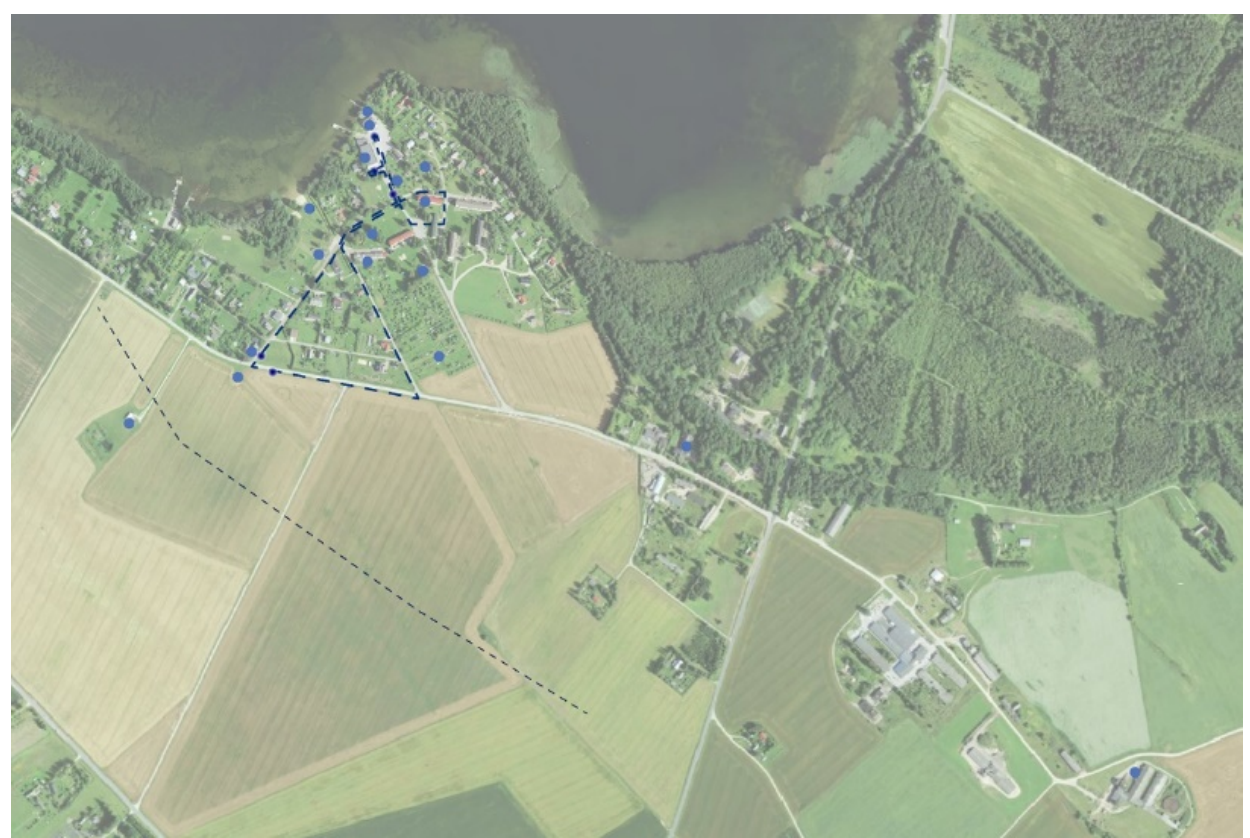

Figure. 5. The results of Go-Along interview on foot (source: the authors).

\section{Results}

There was a joke told by one of the interviewees that really captured the essence of that time. "For capitalism, it is competition that provided success, for socialism, it was connections." (T. Aruoja, interview, 13 February 2018) Although this 'socialist competition/emulation' was a strong motivator in the later decades, the main driving force was the bond between people who worked together. This also includes the need to 'know the right people' if something needed to get done.

However, "Avangard" wasn't socially as united, as one would assume. The kolkhoz was made up from three departments, two of which had joined later as part of a merging of smaller kolkhoz units. They worked together but kept to themselves as social groups. All of the interviewees were from the oldest department - Äksi. Within that area, people were close. "By the 1980s, a kind of family had developed. Old problems were a bygone. Things could be acquired, we had an apartment, we got paid. There was a unity between people and everyone was friendly and knew each other. It's not like that anymore." (A. Priks, interview, 13 February 2018).

"I feel that the tightest bond was formed when the kolkhoz was successful because that's when a lot of events were organised" (A. Priks, interview, 13 February 2018). At the heart of those events was the culture centre. For a place as large (or small) as Äksi, the number of services and events was remarkable. They had regular movie nights twice a week, held concerts that also featured the stars of that era such as Anne Veski and Vello Orumets; nearly all the theatres in Estonia performed there at least once. There were also evening dances, an amateur orchestra, a mixed choir, a mixed ensemble, a children's ballet group, real ballet, ladies' gymnastics group, folk dancing, and a drama club. The stage in the culture house building was no less remarkable. Rudolf Sepp dedicated his life to handcraft the entire wooden and metal construction of the stage, curtains and panels used on it. It was one of the finest in the whole State [2]. The kolkhoz had special ties with Vanemuine theatre as already mentioned. Both would 
help each other: Avangard would offer an escape and accommodation for the actors and theatre's foreign guests; the theatre offered to teach children acting, ballet and singing. Each year they would organise sporting events together and give awards to each other. When Vanemuine had a huge birthday, the cake factory made them a cake in the shape of the theatre house.

The cake factory was initially located in the same house as the culture club from 1968. The need behind such a facility was to use the cracked eggs from the henhouse so nothing would go to waste (chicken and egg production were the main outputs of Avangard). They made every kind of pastry and confectionery known in the region at the time, nevertheless, fancier cakes were only made to order. Later the factory and the dispatchers moved to a new building across the road due to the ever-increasing number of employees and work needing to be done. The culture house itself also got an extension in 1984. "This is just a simple extension to give more space to the office workers. Also, the club downstairs will get a new room so we could have something like a bar, so when a person comes to the cinema or a party, it would be more modern" [3].

There was a lot of construction underway in the 1980s. During the decades of the 1970s and 1980s was the time when most of the settlement we now know as Äksi was built. "At first they built the terraced house, then the block housing and the single family homes last. All houses had hot water and central heating. The rent for an apartment was 5 rubles and the water was free" (T. Aruoja, interview, 13 February 2018): "For those who desired to live in a house of their own, plots were given to all who applied and in addition to that, a 5000 rubles loan to build it. If the family lived and worked in the kolkhoz for at least 10 years, they would not need to pay it back" [3]. One of the interviewees whose house was the first to be built in Äksi, said that before they moved to the new house in 1956, the five of them were living on the shore of Soitsjärv, in the henhouse belonging to another family!

In 1992, after the end of the Soviet Union, the kolkhoz closed. A committee was formed to decide on how to divide the kolkhoz's common assets. "Different units started to work independently. After a while, they started to close down. The Igavere department was the only one that continued working as a whole because the manager took it all over. Larger units could have worked as a cooperative and perhaps would have survived (A. Priks, interview, 13 February 2018)". Most of the people kept living where they were before, as they could buy the apartments given to them with privatization vouchers. Some would become entrepreneurs in their former field of work. Some would go into politics, for example the former agronomist became the municipality mayor.

"We stopped having a vegetable garden when our friend who drove a tractor died. After the end of the collective farm there were no more places to find someone like that. Everybody stopped having a vegetable garden because of that." (A. Priks, interview, 13 February 2018). Alanen [4] has found that the machines used in the kolkhoz were too powerful, and too few, to be used by a single family for a small farm. Often, they ended up in the hands of one or a group of people as a result of secret agreements, thus becoming unavailable for the smaller family farms that emerged from the restructuring of land (usually based on the original farm boundaries from before collectivisation). During a committee meeting at the end, Virve Ramm said "Don't take for yourselves more than you can love". Every person interviewed shared the same opinion that people got greedy and didn't keep a sustainable future in mind when diving the properties.

"I feel sorry for all of that ending, there was a lot that was positive. The trips, the events. The second half of the 1980s wasn't at all bad, just the red part of my job. But all the systems were working, and people had a job, and everyone cared for each other" 
(A. Priks, interview, 13 February 2018). "Think of what the collective farms would be by now! We started to build such huge facilities in the end, grand plans for new production." (T. Aruoja, interview, 13 February 2018). "Now everybody just keeps to themselves" (M. Kuul, interview, 13 February 2018).

\section{Conclusions}

The settlement of Äksi would not be there today without the kolkhoz. The block houses with extensive fields behind them and lake Saadjärv in front still tell the stories of when cakes were made there every day. The three people who were interviewed represented three different sides of the kolkhoz, yet how they viewed the period was similar in the emotional backdrop that could be felt in the way they spoke. Each spoke with pride in their accomplishments, happiness in the friends and acquaintances they had made, and some sadness for it all being over. Their hard work brought the kolkhoz to the success that was foretold in its name, with Chairman Beek leading it with his modern ideas. The unusual loan system he set up, intended to attract new people to live permanently in Äksi was a success. One of the interviewees still lives in the first house built there. The methods used for memory collection produced a diverse collection of information from various angles. This helped to recreate and understand spatial connections between the environment and the people living within it. Memories are a way to discover invisible layers of information that is not possible to be read from cartographical analysis, while still being of great importance to understand an area comprehensively. Clearly, three interviews do not convey the complete sense of a place but this work is only able to report on these; more will be undertaken in the near future

\section{Acknowledgements}

MODSCAPES is a collaborative research project funded under the HERA - Humanities in the European Research Area 3rd Joint Research Programme dedicated to "Uses of the Past" (20162019). This project has received funding from the European Union's Horizon 2020 research and innovation programme under grant agreement $n^{\circ} 649307$

\section{Short resumes}

Kaja Veddel MSc is a landscape architect and recent graduate of the master programme in landscape architecture at the Estonian University of Life Sciences. This paper is based on her master thesis completed in 2018.

Martti Veldi MSc is an archaeologist and a Junior Researcher at the Estonian University of Life Sciences in Tartu, Estonia. He is also an inspector in the Estonian Heritage board responsible for identifying and protecting cultural heritage monuments.

\section{References}

1. KUHLMANN, F.; BELL, S.; VELDI, M. 2017. Research methods for work package 2: Physical legacies (Lead: P15-EMÜ, Co-lead: PI2-POLIMI). Unpublished working paper, MODSCAPES. 
2. SEPP, K.H. 2001. Tartu vald. Ma tahaksin kodus olla... [Tartu Municipality. I would like to be at home ...], Tartu - Lähte, Levileht.

3. Tere hommikust, maarahvas!: TERE HOMMIKUST PÕLLUMEHED! [Good morning country people! Good morning farmers!] (1984). "Avangardi kolhoosi 35 aastat" [The Avangard collective farm turns 35]. [Radio] EESTI RAADIO. 25 March. Retrieved from: http://arhiiv.err.ee/guid/13093 [available on 14 March 2019].

4. ALANEN, I. 1999. "Agricultural policy and the struggle over the destiny of collective farms in Estonia", Sociologia Ruralis, vol. 39, n 3: 431-458.

DOI: https://doi.org/10.1111/1467-9523.00117 